\title{
It was my cancer: Lessons Learned about Bullying from Perceived Sexual $\&$ Gender Minority Youth
}

\author{
Alexandra Marshall ${ }^{1}$ \\ ${ }^{1}$ Department of Health Behavior and Health Education, Fay W. Boozman College of Public Health, University of \\ Arkansas for Medical Sciences, Little Rock, AR, United States \\ Correspondence: Alexandra Marshall, Department of Health Behavior and Health Education, Fay W. Boozman College \\ of Public Health, University of Arkansas for Medical Sciences, Little Rock, AR, United States.
}

Received: February 26, 2016

Accepted: March 30, 2016

Available online: April 1, 2016

doi:10.11114/ijsss.v4i5.1412

URL: http://dx.doi.org/10.11114/ijsss.v4i5.1412

\begin{abstract}
Bullying is often defined as repeated acts of aggression that occur over time in a relationship involving a power imbalance. Bullying of perceived sexual and gender minority youth - which can also be interpreted as homophobic bullying - is a form of aggression intended to make a young person feel marginalized or unwelcome due to their perceived sexual orientation, gender identity or gender expression. Research has linked bullying to various health effects similar to those experienced by survivors of traumatic stress or intimate partner violence. Few studies have examined the experiences of bullying directly from the perspectives of sexual and gender minority youth. Interviews $(\mathrm{n}=16)$ in this exploratory and descriptive study revealed several common themes. Those discussed are that "bullying is serious" (i.e. it was my cancer.), and "survivors use power language" describing their experiences (e.g. push through and be strong.). Youth serving professionals ought to reconsider using the term bullying and perhaps re-conceptualize this phenomenon as a form of interpersonal violence to more appropriately address it in schools.
\end{abstract}

Keywords: bullying; LGBTQ youth; sexual and gender minority; survivors; discrimination

\section{Introduction}

Adolescence is a pivotal time of development in an individual's life that is often wrought with dramatic changes and adjustments. It can be confusing for the adolescent who is directly experiencing their life changes as well as for the parents who are charged with nurturing the adolescent and for other adults who interact with - and have the potential to impact - youth during this period (Lerner \& Galambos, 1998). Adding to this confusion, bullying is a real and relevant issue affecting many of today's adolescents in the United States. Numerous news stories have depicted the unfortunate reality that too many youth have committed suicide because of this preventable behavior.

\subsection{Defining Bullying}

Bullying can be characterized by repeated aggressive acts occurring over time in a relationship that consists of a power imbalance (Olweus, 1994), and it is this perceived power imbalance that often keeps the victim from being able to defend him/herself (Espelage \& Swearer, 2003). Espelage and Swearer (2003) suggest that one commonality among the many definitions of bullying is that it is a "subset of aggression;" therefore, the literature on aggression can be used to understand the phenomenon of bullying (Espelage \& Swearer, 2003). Bullying has been typically categorized as a form of proactive aggression because those who bully others are commonly selecting their targets with little incitement and are bullying their victims for an extended time period (Espelage \& Swearer, 2003). Bullying can be distinguished from other forms of aggression based on the categorization of direct and indirect aggression (Espelage \& Swearer, 2003). Direct or overt forms of aggression involve physically fighting or verbally threatening another person to his/her face; this differs from indirect or covert forms of aggression, which often involve a third-party and types of verbal aggression, such as spreading rumors, teasing, or calling someone unkind names (Espelage \& Swearer, 2003). Relational aggression, coined by Nicki Crick and her colleagues, is another way individuals are bullying others; it is a form of aggression with the intention of damaging a relationship (Espelage \& Swearer, 2003) or using a relationship with the intent to harm someone (Crick \& Grotpeter, 1996).

The most common types of bullying are verbal and social followed by physical bullying and cyberbullying which occur less often (Stopbullying.gov, n.d.). Most bullying takes place at school or at common gathering places in the community 
for youth (Stopbullying.gov, n.d.). According to the National Center for Education Statistics and the Bureau of Justice Statistics (2011), approximately $25 \%$ of students in the United States report having been bullied at school. Research suggests that nearly $30 \%$ of young people admit to having bullied others, and $70 \%$ of young people and school staff report witnessing bullying at school (Bradshaw, Sawyer \& O'Brennan, 2007). However, looking at subgroups of youth, sexual and gender minority youth appear to be disproportionately affected by bullying (Kosciw et al. 2014).

\subsection{Homophobic Bullying}

Homophobic bullying is a type of behavior or language that is intended to make a young person feel marginalized or unwelcome due to their perceived sexual orientation, gender identity, or gender expression (The Rainbow Project, 2012). Perceived sexual and gender minority (SGM) youth are those youth who may identify as lesbian, gay, bisexual, transgender, or queer (LGBTQ) or who may be perceived by their peers to be LGBTQ even if they have not yet identified that way or been "out" with their identity. According to the 2013 National School Climate Survey conducted by the Gay, Lesbian and Straight Education Network (GLSEN), the majority (74.1\%) of the sexual and gender minority youth reported being verbally harassed at school in the past year for their perceived sexual orientation (2014). Due to the hostile school climate, many of these youth felt unsafe either because of their sexual orientation $(55.5 \%)$ or because of their gender expression (37.8\%) (Kosciw et al. 2014).

\subsection{Effects of Bullying}

Research examining bullying in schools has revealed that the students involved can experience long-term, negative health consequences. Of particular interest for this project are the victims of bullying. Youth who are victims of bullying are more likely to suffer from mental health problems such as depression, anxiety and low self-esteem and are more likely to participate in health risk behaviors, such as abusing substances, engaging in sexual risk behaviors or having suicidal ideations or attempts (Almeida, et al, 2009; Bontempo \& D'Augelli, 2002; Espelage, et al., 2008; Espelage \& Swearer, 2003; Hawker \& Boulton, 2000; McDougall, Vaillancourt \& Hymel, 2009; Liu \& Mustanski, 2012). Other researchers have found that verbal abuse experienced in high school was strongly associated with the effects of experiencing traumatic stress, such as depression, anxiety and sleep disturbances (D'Augelli, Pilkington \& Hershberger, 2002). Thus, with these serious health effects, labeling the harassment, discrimination or abuse experienced by victims simply as bullying seems inadequate.

\subsection{Purpose of the Study}

Research on adolescent development has not typically assessed bullying through interviews with the victims in a way that considers the scope of its impact. The study presented aimed to improve our understanding of bullying, how it is defined by victims, and how it impacts the health and well-being of adolescents, especially for this marginalized group that is disproportionately affected. The purpose of the study conducted was to examine and describe experiences of bullying among perceived sexual and gender minority (SGM) youth.

\section{Method}

\subsection{Participants}

This project collected data directly from the population of interest. Participants were recruited using a purposive sampling strategy. Participants self-selected into the study if they were between ages 15 and 20 and had been bullied based on their actual or perceived minority sexual orientation or gender identity. Participants were not asked to disclose their sexual orientation or gender identity at any point in the project. They may have self-identified as lesbian, gay, bisexual, transgender, queer or questioning, or they may have been heterosexual youth who were bullied because they were perceived to identify with a minority sexual orientation or gender identity. A total of 16 youth participated in the study. The majority of the participants were white $(n=13)$ and a little more than half were cisgender males $(n=9)$. They all resided in a Midwestern state in the United States. The average age of the participants was 18 years old.

\subsection{Procedure}

The project began in the summer of 2011. The first month of the project focused on building rapport with various youth service agencies in a Midwestern state in the United States that were supportive of sexual and gender minority youth to obtain permission for recruitment. Over the next six months, about one dozen visits were made in total to the various sites for recruitment. Fliers with a brief description about the project and information on how to contact the researcher if interested in participating were distributed to youth at each visit. The researcher was also granted access to the email lists of the youth service agencies, and recruitment emails were sent through these groups. Youth who were interested were able to contact the researcher via email or cell phone. Youth were also given the option to meet with the researcher on site immediately following the project description and invitation to participate if desired. The researcher also coordinated with the leaders of one of the youth service agencies to have an office space available for a couple of visits and blocked off a few hours for each visit so interested youth could drop by and share their stories without scheduling 
an appointment.

Once the project was described to interested youth, assent was requested. A number of the participants may not have disclosed their sexual identity to their parent(s) or guardian(s), and they may use LGBTQ youth support services or talk with members of these organizations confidentially. Since youth may have jeopardized their personal well-being by attempting to gain permission from their parents/guardians who may be hostile to the teen's sexual identity, parental/guardian consent was not required. Also, this project called for waiver of a signed consent form that was required for all participants. These forms would be the only record linking them to the study and would be the primary risk factor in potentially causing harm if confidentiality was breached. Requiring parental consent or signed consent was waived by the granting university's Institutional Review Board.

Interviews were conducted face-to-face or via email depending on the participant's access to and comfort with these options and what afforded them the most confidentiality. Particularly for face-to-face interviews, risk was minimized to participants as interviews were conducted at locations that were considered safe spaces for these youth. Many interviews occurred on site immediately following the project description, though several interviews were scheduled at a later time and in a location agreed upon between the participant and the researcher. These interviews were conducted either in the offices of the youth service agencies involved in the project or in the researcher's office. The researcher was available for drop-in interviews during two visits to one of the popular youth agencies and was granted access to one of the offices for this purpose.

Data collection took approximately four months beginning in late 2011 and carried into 2012. Participant confidentiality was assured and maintained as the youth were given pseudonyms for their names to be used in the analysis of the interviews. Once saturation, or the redundancy of data, was experienced, 16 interviews had been conducted and data collection ceased. Thirteen interviews were conducted in person and audio recorded, and three interviews were conducted via email. The face-to-face interviews lasted from 15 minutes to 1 hour and 15 minutes; although, on average they lasted about 45 minutes. The question and answer exchange via email was typically succinct but did involve multiple exchanges. Participants were emailed the study information sheet and the questions. They replied with their responses, and then the researcher sent an email with follow-up questions for clarification to which the participants replied.

Participants were thanked for sharing their experiences and given $\$ 20$ cash if the interview was conducted in person or a link to an e-gift card worth an equal amount if the interview was conducted via email. Participants were asked whether or not they were willing to be contacted for follow-up interviews, and they could determine if and how they would like to be contacted. All of the participants were willing to be contacted for follow-up questions.

The recorded interviews were transcribed using a professional transcription service. A thematic analysis was conducted using all the interview data. Themes identified were confirmed with the participants who expressed interest in seeing the findings. The findings from the analysis are intended to fully and accurately describe the bullying experienced by the participants.

\subsection{Data Analysis}

The interview transcripts were initially analyzed in an iterative process over the course of three months beginning in the spring of 2012 using basic framework analysis. The themes identified in the transcripts were confirmed with a group of qualitative research colleagues who acted as peer debriefers to look for possible bias in the coding. No systematic bias was found in the initial coding. To further support the objective validity claims, the researcher conducted member checks by sharing the coded themes with the participants who expressed interest in seeing the findings. This allowed the participants to confirm that their experiences were accurately represented.

\section{Results}

There were several compelling themes that arose from the interviews, including: bullying is serious; gender nonconformity is a common factor in being bullied; resilience among victims (or survivors) is noteworthy; support systems are crucial; and, bullying survivors use power language (Marshall, 2012). A portion of these thematic findings have been published (Marshall et al. 2015). However, as is the case with many qualitative studies, more findings are available than can be presented in one publication (Marshall, 2012). The themes selected for this manuscript explore the severity of the bullying experienced and the language used to discuss these experiences.

\subsection{Theme: Bullying is Serious}

One theme that was expressed by virtually all of the participants was that bullying is serious, and it should be taken seriously. Furthermore, being bullied for your actual or perceived sexual orientation was considered to be more difficult to cope with than being bullied for being overweight or for having acne, for example, which were considered characteristics that had traditionally incited bullying. 
Participant Seth: It's not as much as beating cancer but it feels like it is to me. It was my cancer in a way......... I think that people need to take it more seriously. I think a lot of school administrations are stuck back in archaic days where bullying did mean you're chubby, you four eyes, you have a pizza face and bullying needs to be looked at from a much, mисh, mисh more serious point of view.

Bullying was also considered to be "psychological warfare." The instances shared by the participants had an impact on their identity and on the mental and emotional health. As another participant, Shanna said, this is because "words stay with you." Many of the participants have battled depression and suicidal ideation as a result of the hateful words used to harass them on a regular basis. Thus the majority of participants also expressed a desire for bullying to be taken more seriously by schools and communities. Seth also mentioned that bullying has often been chalked up to "boys will be boys" but he went on to say "and luckily I survived it!" Using the verb "survived" this participant illustrates the harsh reality that bullying today is severe and problematic.

\subsection{Theme: Power Language}

Another important theme that emerged from the interviews was the use of power language. This term is being used in this context to encompass language that connotes the use of power. Often participants used words to indicate their struggle to overcome hardship and alluded to an imbalance of power. The youth used phrases to describe their experience such as, "feeling degraded," or when offering advice to other youth who may be victimized as well, they used phrases such as the following: "push through;" "be strong;" and "don't let it beat you." This is language that is commonly used with the overcoming obstacles.

In addition, language was also used to discuss surviving their experiences of being bullied. This sentiment was especially noticed in advice to victims. Examples of this language include: "stick it out;" "get through it;" or "it gets better." These phrases imply using less force to cope with being bullied but still offer encouragement. This language is also commonly associated with the concept of survivorship.

\section{Discussion}

Regarding the first theme, these findings illustrate the severity of bullying. Bullying is not something to be taken lightly; "it's not four eyes, pizza face." Instead, bullying is serious. "It was my cancer;" "it is a killer and it's a painful death." As stated previously, a substantial amount of research has shown that youth who are victims of bullying are more likely to suffer from mental health problems such as depression, anxiety and low self-esteem and are more likely to participate in health risk behaviors, such as abusing substances, engaging in sexual risk behaviors or having suicidal ideations or attempts (Almeida, et al, 2009; Bontempo \& D'Augelli, 2002; Espelage, et al., 2008; Espelage \& Swearer, 2003; Hawker \& Boulton, 2000; McDougall, Vaillancourt \& Hymel, 2009; Liu \& Mustanski, 2012). These are serious health outcomes of bullying. Furthermore, the Society for Adolescent Medicine has taken the position that bullying is simply and unequivocally an unacceptable behavior among youth (2005). Their position also supports the sentiment shared by the participants that bullying should not be seen as a normative behavior.

Additionally, using power-charged language was another compelling theme found in these interviews. Looking at the phrases used, interestingly these are often the types of phrases of encouragement given to individuals who are battling diseases or overcoming other severe obstacles in life. The notion that bullying is something to be survived also speaks to the first theme mentioned by participants who thought bullying should be taken more seriously.

The themes discussed present a need to address bullying in a very different way than it may have been addressed by schools or community groups in the past. The notion that bullying is serious suggests that it should be taken seriously in much the same way that other issues involving peer relations, such as sexual harassment or other forms of verbal or physical harassment or assault, have been addressed. Perhaps youth serving professionals who are involved in educating youth may need to reframe bullying in a way that conceptualizes it along the same lines as other forms of violence. After all, the health outcomes of bullying are similar to those experienced by others who have endured other forms of interpersonal violence or aggression. For instance, women who experienced physical and/or psychological intimate partner violence have been shown to have greater incidence and severity of depression and anxiety, post-traumatic stress disorder, and suicidal thoughts compared to women who had not experienced such violence (Pico-Alfonso, Garcia-Linares, Celda-Navarro, Blasco-Ros, Echeburua, \& Martinez, 2006). Thus, in order to have an impact on mitigating the bullying experienced by youth perhaps re-conceptualizing it and reframing it as a form of interpersonal violence is needed.

In addition, the findings lend support to the need for protective measures to be adopted by school systems. Considering that most of the instances of bullying or harassment reported in their interviews were stemming from issues related to gender nonconformity, educating students and school personnel about diversity and demonstrating respect for diversity could possibly ameliorate this issue. While some schools may have such programming currently incorporated into their 
curricula and may have policies reflective of respect for diversity, others simply do not. Alternatively, some schools may have the programs that could foster respect for cultural diversity (e.g.. having a gay-straight alliance) or policies that could protect cultural diversity (i.e. an enumerated anti-bullying or anti-discrimination policy that protects students on the basis of sexual orientation or gender identity) but many of these schools do not implement the programs or enforce the policies. The stories of these youth support the need for that to change.

Knowing the challenges that adolescents endure in their development as they are trying to reconcile the flurry of changes that they are experiencing simultaneously physically, mentally, emotionally, socially and even behaviorally in order to develop their identities as individuals (APA, 2002), it is understandable that being bullied for trying to be what one knows to be as his/her true self must amplify this challenge remarkably. Furthermore, in Russell's (2003) methodological review of the literature, he indicated that the previous decade of research examining the risk factors for suicide among sexual minority youth, victimization is of particular importance for this group. While harassment may be a risk factor for suicide for all adolescents, research has shown that the forms of victimization experienced by sexual minority youth differ from that experienced by other youth because it is harassment targeting sexual minority status (Russell, 2003; Meyer, 2003). The experiences shared by the participants in this study speak to that. This is because this particular form of harassment targets an aspect of an individual's identity. While researchers have pointed out that adolescents are developing their self-concept and self-esteem (APA, 2002) based on their own and others' appraisals of themselves (Sebastian, et al, 2008), being attacked for an element of one's self that is a part of the core of his/her being may be difficult to reconcile mentally and emotionally. Thus, an adolescent may have particular difficulty coping and developing healthily as a result of being victimized for his/her sexual minority status which is a part of his/her identity. Furthermore, when youth serving professionals think about and use the term bullying to identify and to describe the phenomenon experienced by all youth but particularly by SGM youth, they may need to reconsider the term; the connotation of bullying carries little weight in comparison to other terms that may more appropriately apply, such as harassment, abuse, discrimination or interpersonal violence.

\subsection{Limitations}

The primary limitation is having a relatively homogeneous participant population. Since participants were sampled from community organizations and support groups that served sexual and gender minority youth in a Midwestern state, this participant sample is primarily white, middle class and having similar ideals. This is a recognized limitation as far as being able to generalize the findings to the greater population of the United States; however, this study is intended to be exploratory and descriptive of the desired participant population. Secondly, it is difficult to draw conclusions about the prevalence of bullying since self-identifying as having been bullied was an enrollment criterion for this study. Thus, by design, all of the participants were bullied, and given the self-selection into the study, this may be a group of adolescents for whom bullying was particularly salient and serious.

\subsection{Conclusions}

From the findings, one can conclude that bullying is serious; it has a serious impact on the mental and emotional health of victimized youth, and it should be taken seriously by adults. Youth serving professionals must recognize the inadequate language currently used to identify behaviors as bullying. Bullying may need to be re-conceptualized as a form of interpersonal violence in order to be more appropriately addressed.

\section{Acknowledgements}

Thank you to all of the youth serving agencies that facilitated recruitment for this project and a special thank you goes to the youth who shared their stories with me. I am grateful for them, and I hope that sharing these elements of their experiences will foster a climate of inclusivity and support.

\section{References}

Almeida, J., Johnson, R. M., Corliss, H. L., Molnar, B. E., \& Azrael, D. (2009). Emotional distress among LGBT youth: The influence of perceived discrimination based on sexual orientation. Journal of Youth and Adolescence, 38(7), 1001-1014. http://dx.doi.org/10.1007/s10964-009-9397-9

Bontempo, D. E., \& D'Augelli, A. R. (2002). Effects of at-school victimization and sexual orientation on lesbian, gay, or bisexual youths' health risk behavior. Journal of Adolescent Health, 30, 364-374. http://dx.doi.org/10.1016/S1054-139X(01)00415-3

Bradshaw, C. P., Sawyer, A. L., \& O’Brennan, L. M. (2007). Bullying and Peer Victimization at School: Perceived Differences between Students and School Staff. School Psychology Review, 36(3), 361-382.

Crick, N. R., \& Grotpeter, J. K. (1996). Children's treatment by peers: Victims of relationship and overt aggression. Development and Psychopathology, 8, 367-380. http://dx.doi.org/10.1017/S0954579400007148 
D'Augelli, A. R., Pilkington, N. W., \& Hershberger, S. L. (2002). Incidence and mental health impact of sexual orientation victimization of lesbian, gay, and bisexual youths in high school. School Psychology Quarterly, 17(2), 148-167. http://dx.doi.org/10.1521/scpq.17.2.148.20854

Espelage, D. L., \& Swearer, S. M. (2003). Research on school bullying and victimization: What have we learned and where do we go from here? School Psychology Review, 32(3), 365-383.

Espelage, D. L., S. R. Aragon, Birkett, M., \& Koenig, B. W. (2008). Homophobic teasing, psychological outcomes,and sexual orientation among high school students: What influence do parents and schools have? School Psychology Review, 37(2), 202-216.

Hawker, D. S. J., \& Boulton, M. J. (2000). Twenty years' research on peer victimization and psychosocial maladjustment: A meta-analytic review of cross-sectional studies. Journal of Child Psychology and Psychiatry and Allied Disciplines, 41, 441-445. http://dx.doi.org/10.1111/1469-7610.00629

Kosciw, J. G., Greytak, E. A., Palmer, N. A., \& Boesen, M. J. (2014). The 2013 National School Climate Survey: The experiences of lesbian, gay, bisexual and transgender youth in our nation's schools. New York: GLSEN.

Lerner, R., \& Galambos, N. (1998). Adolescent development: Challenges and opportunities for research, programs and policies. Annual Review of Psychology, 49, 413-446. http://dx.doi.org/10.1146/annurev.psych.49.1.413

Liu, R. T., \& Mustanski, B. (2012). Suicidal ideation and self-harm in lesbian, gay, bisexual, and transgender youth. American Journal of Preventive Medicine, 42(3), 221-228. http://dx.doi.org/10.1016/j.amepre.2011.10.023

Marshall, A. (2012). Experiences with bullying among youth perceived to be of a minority sexual orientation. (Doctoral dissertation). Retrieved from ProQuest. (3522652)

Marshall, A.,Yarber,W. L., Sherwood-Laughlin, C. M., Gray, M. L., \& Estell, D. B. (2015). Coping and Survival Skills: The Role School Personnel Play Regarding Support for Bullied Sexual Minority Oriented Youth. Journal of School Health, 85, 334-340. http://dx.doi.org/10.1111/josh.12254

McDougall, P., Vaillancourt, T., \& Hymel, S. (2009). What happens over time to those who bully and those who are victimized? In S. Hymel, S. Swearer, Gillette, P. \& Daniels, D. (Eds.) Bullying At School and Online - An Education.com Special Edition. http://www.education.com/static/ebook/education-com-bullying-ebook.pdf

Meyer, I. H. (2003). Prejudice, social stress, and mental health in lesbian, gay, and bisexual populations: Conceptual issues and research evidence. Psychology Bulletin, 129, 674-697. http://dx.doi.org/10.1037/0033-2909.129.5.674

National Center for Education Statistics and the Bureau of Justice Statistics. 2011. "Student Reports of Bullying and Cyber-Bullying: Results from the 2009 School Crime Supplement to the National Crime Victimization Survey." U.S. Department of Education. http://nces.ed.gov/pubs2011/2011336.pdf

Olweus, D. (1994). Bullying at school: Long-term outcomes for the victims and an effective school-based intervention program. In L.R. Huesmann (Ed.), Aggressive behavior: Current perspectives , 97-130. New York: Plenum. http://dx.doi.org/10.1007/978-1-4757-9116-7_5

Pico-Alfonso, M. A., Garcia-Linares, M. I., Celda-Navarro, N., Blasco-Ros,C., Echeburua, E., \& Martinez, M. (2006). The impact of physical, psychological, and sexual intimate male partner violence on women's mental health: Depressive symptoms, posttraumatic stress disorder, state anxiety, and suicide. Journal of Women's Health, 15(5), 599-611. http://dx.doi.org/10.1089/jwh.2006.15.599

Russell, S. T. (2003). Sexual minority youth and suicide risk. American Behavioral Scientist, 46, 1241-1257. http://dx.doi.org/10.1177/0002764202250667

Stopbullying.gov. (n.d.). U.S. Department of Health and Human Services. Retrieved from http://www.stopbullying.gov/at-risk/groups/lgbt/lgbtyouthtipsheet.pdf

The Rainbow Project. (2012). What is homophobic bullying? Retrieved from http://www.rainbow-project.org/services/education-services/homophobic-bullying

This work is licensed under a Creative Commons Attribution 3.0 License. 